\title{
Prevalence of colour vision deficiency in the Republic of Ireland schoolchildren and associated socio-demographic factors
}

\author{
Síofra Harrington \\ Technological University Dublin, siofra.harrington@tudublin.ie \\ Peter Davison \\ Technological University Dublin, Peter.Davison@tudublin.ie \\ Veronica O'Dwyer \\ Technological University Dublin, veronica.odwyer@tudublin.ie
}

Follow this and additional works at: https://arrow.tudublin.ie/scschphyart

Part of the Optometry Commons

\section{Recommended Citation}

Síofra Harrington, Peter A Davison \& Veronica O'dwyer (2021) Prevalence of colour vision deficiency in the Republic of Ireland schoolchildren and associated socio-demographic factors, Clinical and Experimental Optometry, 104:1, 48-55, DOI: 10.1111/cxo.13072

This Article is brought to you for free and open access by the School of Physics \& Clinical \& Optometric Science at ARROW@TU Dublin. It has been accepted for inclusion in Articles by an authorized administrator of ARROW@TU Dublin. For more information, please contact arrow.admin@tudublin.ie, aisling.coyne@tudublin.ie, gerard.connolly@tudublin.ie.

Funder: TU Dublin; Opticians Board; Association of Optometrists Ireland

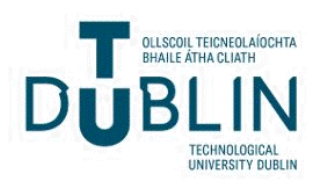




\section{Prevalence of colour vision deficiency in the Republic of Ireland schoolchildren and associated socio-demographic factors}

\author{
Síofra Harrington (D) PhD DipOphthOpt \\ FAOI
}

Peter A Davison PhD MSc BSc (Optom) FAOI

Veronica O'Dwyer PhD DipOphthOpt FAOI

School of Physics, Clinical and Optometric Sciences, Technological University Dublin, Dublin, Ireland E-mail: siofra.harrington@dit.ie

Submitted: 29 September 2019

Revised: 13 January 2020

Accepted for publication: 19 March 2020
Clinical relevance: Early screening is essential to counsel schoolchildren with congenital colour vision deficiency (CVD) in determining their future career path and to advise teachers of the impact of CVD on classroom difficulties.

Background: Congenital CVD is an X-linked genetic abnormality relatively commonplace in humans. This study aimed to determine the prevalence of congenital CVD in the Republic of Ireland schoolchildren and associated socio-demographic factors.

Methods: A total of 1,626 schoolchildren (882 boys and 744 girls), in two age groups (728 aged 6-7 years and 898 aged 12-13 years) were examined from randomly selected schools. Colour vision testing was carried out using the Richmond Hardy-Rand-Rittler pseudoisochromatic test for colour vision (fourth edition); diagnostic plates were used to determine CVD type and extent if participants failed to identify symbols on the screening plates.

Results: CVD was detected in 73 boys (8.3 per cent, 95\% confidence interval (Cl) 6.6-10.3) and in 13 girls (1.8 per cent, 95\% Cl 1.0-3.1, p < 0.001). As expected, deutan (boys 4.8 per cent, girls 0.8 per cent) was the most common type of CVD, followed by protan (boys 1.7 per cent, girls 0.1 per cent), unclassified red/green CVD (boys 1.2 per cent, girls 0.8 per cent) and then tritan (boys 0.5 per cent). One case of achromatopsia was detected based on failure on all diagnostic plates. Traveller participants (boys 21.0 per cent, girls 8.6 per cent) had a higher CVD prevalence than their White non-Traveller (boys 7.2 per cent, girls 1.0 per cent) and non-White (boys 5.4 per cent, girls 1.1 per cent) counterparts (odds ratio $3.00,95 \% \mathrm{Cl}$ $1.1-8.1, \mathrm{p}=0.006$ ). In boys, CVD was also associated with twin birth (odds ratio $2.7,95 \% \mathrm{Cl}$ $1.1-6.7, p=0.03)$ and low birthweight $(p=0.04)$.

Conclusion: This investigation of CVD in the Republic of Ireland schoolchildren should alert clinicians to the association between CVD and Traveller ethnicity, twin birth and lower birthweight. The prevalence of CVD found was similar to previous studies involving predominantly White populations and higher among Traveller participants; hence, counselling regarding inherited anomalies in the Traveller community is recommended. Early screening is essential to counsel schoolchildren with CVD in determining their future career path and to advise teachers of the impact of CVD on classroom difficulties.

Key words: Colour blind, colour vision, Ireland, schoolchildren, Travellers

Colour vision deficiency (CVD) manifests itself in confusion of and reduced sensitivity to colour differences and may be congenital or acquired. ${ }^{1}$ The most prevalent forms of congenital CVD are inherited in an X-linked recessive manner, which results in a higher CVD prevalence in the male population. ${ }^{2}$ The prevalence of CVD reported in different geographical locations varies between two per cent and eight per cent in boys, ${ }^{3-5}$ and 0.4 per cent to 1.7 per cent in girls. ${ }^{6}$ Ethnic differences in CVD prevalence have been reported. ${ }^{5,7}$ According to the Hardy-Weinberg principle the prevalence of inherited non-fatal abnormalities (allele and genotype frequencies), ${ }^{8}$ such as inherited CVD, does not vary inter-generationally in the absence of other evolutionary influences. ${ }^{6}$ However, genetically isolated communities where marriages take place between individuals with a common ancestor are not in HardyWeinberg equilibrium, and prevalence estimates may vary over time. ${ }^{6}$

Normal colour vision is mediated by cones variously containing blue-sensitive, greensensitive and red-sensitive opsin pigments sometimes referred to respectively as short-, medium- and long-wave sensitive pigments. ${ }^{9}$ Deuteranomalous and protanomalous deficiencies are characterised by a greater than normal degree of overlap of spectral sensitivities, a shift in peak sensitivity occurring in the green-sensitive or red-sensitive pigment, respectively. ${ }^{9}$ More severe colour vision problems are associated with deuteranopia and protanopia, which occur when green- or redsensitive pigment respectively is absent. ${ }^{1}$ Much more rarely, a CVD is caused by either absence or shifted peak spectral sensitivity of blue-sensitive pigment (tritan CVDs), or by the 
presence of only a single type of photopigment (achromatism). ${ }^{1}$

People with CVD have been precluded from certain occupations as they are at a distinct disadvantage when performing specific visual tasks. ${ }^{10}$ For example, some occupations have statutory colour vision requirements, which may prevent people with CVD from joining the army or the navy. ${ }^{11}$ This varies from country to country. ${ }^{12}$ Moreover, CVD presents a considerable disadvantage when working in medical and paramedical professions due to difficulties assessing patient pallor, inflammation, dip-stick colour and other colour-coded diagnostic tests and in differentiating diseased tissue. $^{13}$

Of further concern, prior research reported 60 per cent of anomalous trichromats and 30 per cent of dichromats were unaware of their CVD in school. ${ }^{14}$ Similarly, a study involving Italian schoolchildren noted 96 per cent of CVD schoolchildren in middle school and 65 per cent of CVD university students were unaware of their CVD. ${ }^{15}$ Additionally, low selfesteem and feelings of inferiority consequent to challenges in school due to CVD have been reported. ${ }^{16}$ Hence, awareness of CVD in schoolchildren is essential to enable teachers to develop adaptive teaching strategies. This is critical in situations where colour is used as a didactic tool, to ensure children with CVD do not miss essential information, thus helping children with CVD avoid frustration as they progress through their early school years and also avoid disappointment in career choice when leaving post-primary school. ${ }^{17}$ However, there is a paucity of contemporary data on CVD prevalence in European children.

The last study to report CVD prevalence in Northern Ireland (United Kingdom), which is the closest comparator to the present study, was in 1957 when 6.9 per cent of male entrants to Queens University in Belfast were recorded as colourblind. ${ }^{18}$ The present study reports CVD prevalence in the Republic of Ireland (henceforth 'Ireland') schoolchildren and explores the relationship between CVD and socio-demographic variables.

\section{Methods}

This study was a component of the Ireland Eye Study, an observational population-based study of visual and ocular status among schoolchildren in Ireland. Ethics approval was obtained from the Technological University Dublin Research Ethics Committee and adhered to the Tenets of the Helsinki Declaration of Human Studies. The study methodology, sampling, recruitment protocols and participation rates were previously published. ${ }^{19}$ In summary, stratified random cluster sampling was employed in participating in school selection. Schools were stratified by primary/post-primary status, urban/rural status, socioeconomically disadvantaged/advantaged status.

Ethnicity was categorised on the basis of self-reporting by the participants' parent/ guardian as White (79.3 per cent, 1,290 participants), Traveller (9.3 per cent, 151 participants) and non-White (11.4 per cent, Black 80 participants, East Asian 51 participants, South Asian 49 participants). Although White, the Traveller community is the largest indigenous ethnic minority in Ireland, having primarily separated from the settled population in Ireland approximately 360 years ago. ${ }^{20}$ The Traveller community received legal ethnic minority status in Ireland in 2017.

There is a higher prevalence of recessive diseases, ${ }^{21}$ such as galactosaemia, Hurlers syndrome and I-cell disease in the Irish Traveller community, due to social isolation and consanguineous marriages. ${ }^{21}$ As per the 2016 Irish census, 1.5 per cent of 5-14-year-old children were Traveller; however, the de facto number is likely to be larger; Irish Travellers are White Irish, yet, as per the 2016 Irish census, one had to declare as White Irish or Irish Traveller. Furthermore, there is evidence of greater undercoverage of the Traveller population in the Irish census when compared to the settled community. ${ }^{22}$

The Statistical Package for Social Sciences (SPSS) version 24 (IBM Corp, Armonk, NY, USA) was used for most analyses. Anonymised study data were entered directly into an SPSS database. The statistical package RStudio version 1.1.456 (R Foundation for Statistical Computing, Vienna, Austria) was used to generate random numbers for the sampling procedure and also to provide prevalence data confidence intervals (Cls). Demographic factors associated with CVD prevalence were identified using multinomial logistic regression with subjects without CVD as the reference group. Myopia was defined as spherical equivalent refraction $\leq-0.50 \mathrm{D}$, hyperopia as spherical equivalent refraction $\geq+2.00 \mathrm{D}$, and astigmatism as $\geq 1.00 \mathrm{DC}$. Throughout, $95 \% \mathrm{Cls}$ were used.

\section{Examination procedures}

Colour vision testing was examined binocularly using the Richmond Hardy-Rand-Rittler fourth edition colour vision test with the habitual prescription in place at a distance of $70 \mathrm{~cm}$ in natural daylight before instillation of cycloplegic eyedrops. The Hardy-Rand-Rittler test combines suitability for non-numerate subjects with the ability to screen for tritan CVDs with good sensitivity, ${ }^{23,24}$ and consists of four demonstration plates, six screening plates, and 14 diagnostic plates (10 plates for protans and deutans; four plates for tritans). The demonstration plates act as a control; identification of the symbols requires an understanding of instructions and adequate vision but does not require colour vision. Symbols on the subsequent plates consist of coloured spots which lie on the protan, deutan or tritan achromatic confusion loci; the colours become increasingly saturated as the test proceeds. ${ }^{23}$ Participants who failed to correctly identify and locate symbols on any of the six screening plates were tested on the diagnostic plates (pages 11-24) to confirm CVD type and extent. Participants who correctly identified all symbols on the diagnostic plates, but who failed two of the screening plates were categorised as unclassified red/green CVD. Hence, the colour vision fails criterion in the present study was two or more missed plates.

Distance monocular crowded logMAR visual acuities were measured and scored by letter with and without a pinhole using the Good-Lite (Elgin, IL, USA) Sloan letters logMAR chart.

Cycloplegic auto-refraction, at least 20 minutes post-instillation of anaesthetic (Minims proxymetacaine hydrochloride 0.5\%) and cycloplegic eye drops (Minims cyclopentolate hydrochloride 1\%) was followed by dilated direct ophthalmoscopy.

Parents completed a participant and parental history questionnaire detailing birth and medical history. After the examination, the parents/guardians of all participants received a detailed report advising them of study findings and the necessity of any further treatment if required.

\section{Results}

All participants correctly identified and located symbols on the demonstration plates. CVD was identified in 86 participants (5.3 per cent, $\mathrm{Cl}$ 4.3-6.5), of which 48 were deutan (3.0 per cent, $\mathrm{Cl} 2.2-3.9), 17$ protan (1.1 per cent, $\mathrm{Cl}$ 0.6-1.7), four tritan (0.2 per cent, $\mathrm{Cl} 0.1-0.7$ ) and one case of achromatopsia was detected based on failure on both red/green and blue/ yellow diagnostic plates. 


\begin{tabular}{|c|c|c|c|c|c|}
\hline \multirow{16}{*}{$\begin{array}{l}\text { CVD } \\
\text { All }(n=882)\end{array}$} & CVD type & CVD extent & Frequency & Percentage & $95 \% \mathrm{Cl}$ \\
\hline & & & & & \\
\hline & Deutan & & 42 & 4.8 & $3.5-6.4$ \\
\hline & & Mild deutan & 11 & 1.3 & $0.7-2.3$ \\
\hline & & Medium deutan & 14 & 1.6 & $1.0-2.7$ \\
\hline & & Strong deutan & 17 & 1.9 & $1.2-3.1$ \\
\hline & Protan & & 15 & 1.7 & $1.0-2.9$ \\
\hline & & Mild protan & 3 & 0.3 & $0.1-1.1$ \\
\hline & & Medium protan & 6 & 0.7 & $0.3-1.6$ \\
\hline & & Strong protan & 6 & 0.7 & $0.3-1.6$ \\
\hline & Unclassified red/green & & 11 & 1.3 & $0.7-2.3$ \\
\hline & Tritan & & 4 & 0.5 & $0.2-1.2$ \\
\hline & & Medium tritan & 3 & 0.3 & $0.1-1.1$ \\
\hline & & Strong tritan & 1 & 0.1 & No Cl \\
\hline & Monochromatic & & 1 & 1.1 & $\mathrm{No} \mathrm{Cl}$ \\
\hline & Total & & 73 & 8.3 & $6.6-10.3$ \\
\hline \multicolumn{6}{|l|}{ White $(n=709)$} \\
\hline & Deutan & & 32 & 4.5 & $3.2-6.4$ \\
\hline & & Mild deutan & 8 & 1.1 & $0.5-2.3$ \\
\hline & & Medium deutan & 8 & 1.1 & $0.5-2.3$ \\
\hline & & Strong deutan & 16 & 2.3 & $1.3-3.7$ \\
\hline & Protan & & 11 & 1.6 & $0.8-2.9$ \\
\hline & & Medium protan & 5 & 0.7 & $0.3-1.7$ \\
\hline & & Strong protan & 6 & 0.9 & $0.4-1.9$ \\
\hline & Unclassified red/green & & 5 & 0.7 & $0.3-1.7$ \\
\hline & Tritan & & 2 & 0.3 & $0.05-1.1$ \\
\hline & & Medium tritan & 1 & 0.1 & No $\mathrm{Cl}$ \\
\hline & & Strong tritan & 1 & 0.1 & \\
\hline & Total & & 51 & 7.2 & $5.5-9.4$ \\
\hline & Deutan & & 6 & 7.4 & $3.1-16.0$ \\
\hline & & Mild deutan & 1 & 1.2 & $0.6-7.6$ \\
\hline & & Medium deutan & 4 & 4.9 & $1.6-12.8$ \\
\hline & & Strong deutan & 1 & 1.2 & $0.06-7.6$ \\
\hline & Protan & & 3 & 3.7 & $1.0-11.2$ \\
\hline & & Mild protan & 2 & 2.5 & $0.5-9.5$ \\
\hline & & Medium protan & 1 & 1.2 & $0.06-7.6$ \\
\hline & Unclassified red/green & & 6 & 7.4 & $3.1-16.0$ \\
\hline & Tritan & & 2 & 2.5 & $0.5-9.5$ \\
\hline & & Medium tritan & 2 & 2.5 & $0.5-9.5$ \\
\hline & Total & & 17 & 21.0 & $13.0-31.7$ \\
\hline & Deutan & & 4 & 4.4 & $1.4-11.0$ \\
\hline & & Mild deutan & 2 & 2.2 & $0.4-8.4$ \\
\hline & & Medium deutan & 2 & 2.2 & $0.4-8.4$ \\
\hline & Protan & & 1 & 1.1 & $0.05-6.6$ \\
\hline & & Mild protan & 1 & 1.1 & $0.05-6.8$ \\
\hline & Total & & 5 & 5.4 & $2.0-12.8$ \\
\hline
\end{tabular}

Table 1. Prevalence and extent of CVD in 882 male participants in the Ireland Eye Study 


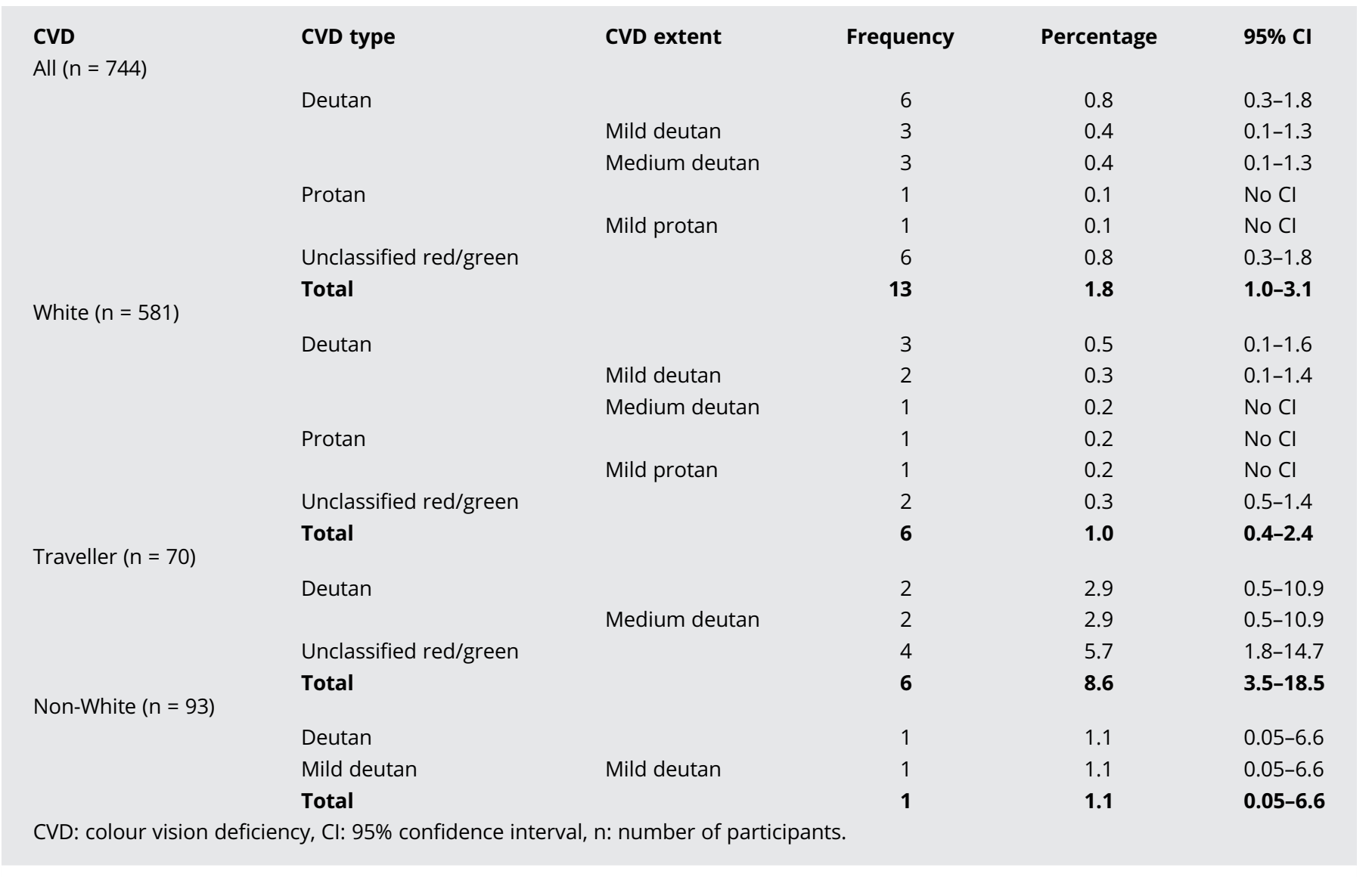

Table 2. Prevalence and extent of CVD in $\mathbf{7 4 4}$ female participants in the Ireland Eye Study

As expected, gender was associated with CVD (odds ratio 5.1, 95\% Cl 2.8-9.1, $\mathrm{p}<0.001$ ). Seventy-three of the 882 boys had CVD $(8.3$ per cent, $95 \% \mathrm{Cl} 6.6-10.3)$, in comparison to 13 of the 644 girls (1.8 per cent, $95 \% \mathrm{Cl} 1.0-3.1)$. From now on, unless otherwise stated, boys and girls are analysed separately (Table 1).

The prevalence of CVD was not associated with age overall (boys, $p=0.16$, logistic regression, girls $=0.53$ ), or within any ethnic group (boys: White $p=0.06$, Traveller $p=0.27$, nonWhite $p=0.25$; girls: White $p=0.08$, Traveller $p=0.11$, non-White $p=0.30$ ). Thus, 6-7-yearold and 12-13-year-old participants are combined for all further analysis.

Among boys with CVD, deutan was the predominant CVD type (boys 57.5 per cent, girls 38.5 per cent), followed by protan (20.6 per cent), unclassified red/green (15.1 per cent) and tritan (5.1 per cent) (Table 1). The four participants categorised as tritan were two sets of twin brothers. Of the 13 girls with CVD, the majority (46.2 per cent) had unclassified red/green, a very mild form of CVD followed by mild deutan (23.0 per cent) and mild protan (7.7 per cent) (Table 2).
Traveller ethnicity was significantly associated with CVD in boys (odds ratio 4.6, 95\% $\mathrm{Cl} 1.6-13.2, \mathrm{p}=0.001$ ) and girls (odds ratio 8.6, $95 \% \mathrm{Cl} 1.1-73.4, \mathrm{p}=0.049)$. Of the Traveller participants, 21.0 per cent $(17 / 81)$ of the boys and 6.6 per cent of the girls $(6 / 70)$ had CVD (Figure 1 and Table 1). Of the White participants, 7.2 per cent (51/708) of boys and 1.0 per cent $(6 / 582)$ of girls had CVD. The corresponding numbers for non-White participants were 5.4 per cent (5/92) and 1.1 per cent (1/9) respectively.

Socio-economic disadvantage was associated with CVD in boys ( $p=0.049$, logistic regression). However, controlling for ethnicity, this association was no longer significant ( $p=0.06$, logistic regression). Urban/rural living conditions were not associated with CVD (boys $p=0.84$, girls $p=0.07$ ) or within any ethnic group (all $p>0.05$ ).

CVD was not associated with myopia (boys $p=0.78$, girls $p=0.41$ ), hyperopia (boys $p=0.81$, girls $p=0.06$ ), or astigmatism (boys $p=0.57$, girls $p=0.99$ ) by logistic regression.

CVD was associated with twin birth (questionnaire response $1,577 / 1,626$ participants
[97.0 per cent]) in boys (odds ratio 2.7, Cl 1.1-6.7, $p=0.04$ ) but not girls ( $p=0.33$ ); CVD prevalence was 18.2 per cent (6/33) among twin boys compared to 7.7 per cent (63/814) among singleton births. Low birthweight (questionnaire response 1,364/1,626 participants [83.9 per cent], odds ratio $1.7,95 \% \mathrm{Cl}$ $1.1-2.8, p=0.04$ ) was also associated with CVD prevalence.

\section{Discussion}

The Ireland Eye Study reports the prevalence of CVD in Ireland. Specifically, using a large randomly selected population-based cohort of schoolchildren in Ireland, this study presents CVD prevalence estimates for White, non-White and Traveller schoolchildren. CVD prevalence in the present study (8.3 per cent boys, 1.8 per cent girls) was higher than reported in 1955 in Northern Ireland male university entrants (6.9 per cent), ${ }^{18}$ and previous studies involving mainly White populations: America (7.5 per cent male, 0.6 per cent female) ${ }^{9}$ and England (6.6 per cent male, 0.4 
$25.0 \%$

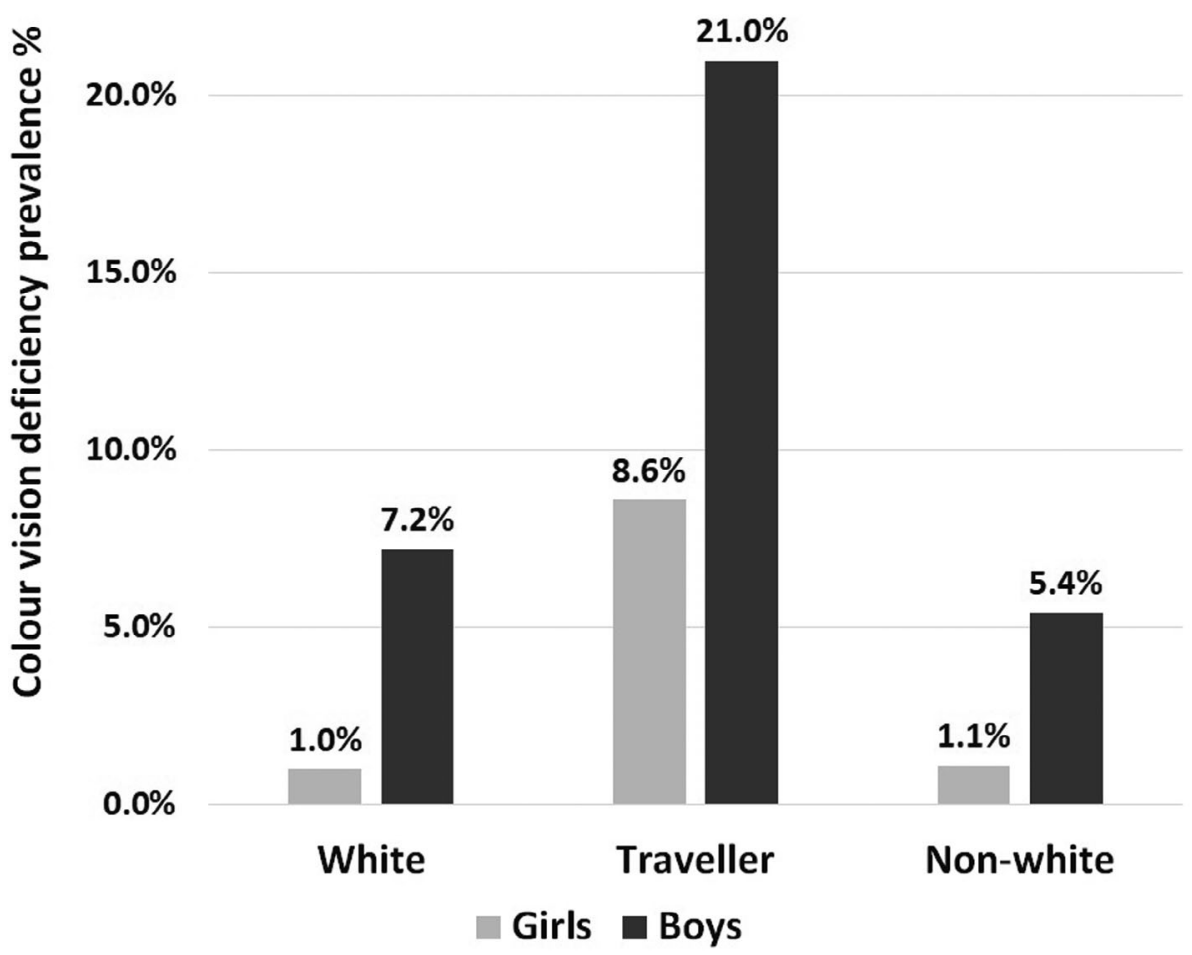

Figure 1. The prevalence of colour vision deficiency in boys and girls in the Ireland Eye Study by ethnic grouping

per cent female). ${ }^{25}$ Lower CVD prevalence was reported in East Asian populations in Korea (5.9 per cent male, 0.4 per cent female), ${ }^{4}$ Singapore (5.3 per cent male, 0.2 per cent female), ${ }_{1}^{1}$ and South Asian studies in India (3.8 per cent male, 0.1 per cent female) ${ }^{10}$ and Nepal (3.9 per cent male, zero per cent female) ${ }^{26}$ (Table 3).

A comparison of study findings to prior studies in other countries is not straightforward due to a variety of factors such as sampling and selection bias associated with nonpopulation-based studies. Large randomly selected population-based studies are essential to prevent bias, ${ }^{6}$ and ensure accurate prevalence estimates with narrow confidence intervals. Precise estimates of CVD in large population-based studies involving White participants reported CVD in approximately eight per cent of males and 0.4 per cent of females. ${ }^{6}$

The present study found a similar prevalence among White male participants (7.2 per cent) and higher among White female participants (1.8 per cent). However, among girls with CVD in the present study the majority had mild CVD with only three participants (0.4 per cent) displaying moderate CVD and no girls presenting with a strong CVD (Table 2). As Ireland is an island and somewhat genetically isolated until relatively recently, the Irish population may not be in the Hardy-Weinberg equilibrium.

Since 1996, there has been a significant increase in the numbers of people migrating to Ireland. In the 2011 census, 12.2 per cent of people living in Ireland were born either in the UK (6.3 per cent) or European Union countries (5.9 per cent). ${ }^{27} \mathrm{~A}$ census question on ethnicity and cultural background was first introduced in 2006 and continued in 2011 and 2016, thereby facilitating a comparison between data. The fastest growing ethnic group in Ireland since 2006 was 'Any other Asian group' (non-Chinese Asian). ${ }^{27}$ As the prevalence of CVD in Asian populations is lower (males between four and five per cent) than White populations (males eight per cent) ${ }^{6}$ future studies in Ireland are recommended to see if changes in ethnic profile in Ireland will influence the CVD prevalence.

The Multi-Ethnic Paediatric Eye Disease Study in the USA involved 4,177 preschool children and found ethnicity to be significantly associated with CVD; among males, CVD prevalence ranged from 1.4 per cent in Black males, 3.1 per cent in Asian males, 2.6 per cent in Hispanic males and 5.6 per cent in White males. ${ }^{5}$ Of the male subjects with CVD, 51 per cent had a deutan defect, and 34 per cent had a protan defect, ${ }^{5}$ in contrast to the present study (62.8 per cent deutan and 21.6 per cent protan) which is closer to other prevalence studies (averaging 67 per cent and 33 per cent). ${ }^{10}$ These differences may reflect differences in CVD screening tests and techniques and the selection of participants. Likewise, the present study found ethnicity was associated with CVD.

While there was no significant difference in overall CVD prevalence between the nonWhite (boys 5.4 per cent, girls 1.1 per cent) and White (boys 6.4 per cent, girls 0.9 per cent) participants, there was a significantly higher CVD prevalence among the Traveller participants (boys 14.8 per cent, girls 2.9 per cent) subgroup, which is a novel finding. Moreover, CVD prevalence among female Travellers (8.6 per cent) was higher than the White (one per cent) and non-White participants (1.1 per cent), and considerably higher than the below one per cent reported for females in the literature. ${ }^{6}$ However, the numbers of females with moderate CVD in the present study was low (White 0.2 per cent, Traveller 2.9 per cent, non-White zero per cent).

There are high levels of autozygosity within the Traveller community in Ireland, which has implications for disease mapping and the provision of public health services. ${ }^{20,21}$

The proportion of usually resident Travellers aged 5-14 years in Ireland in the 2016 census was 1.5 per cent, although this may be an underestimate. Accurately measuring the number of Traveller children in Ireland is challenging, as self-declaration is the only mechanism to capture this data; the reported undercoverage of the Traveller population in the census data further complicates matters. ${ }^{22}$ The significantly higher CVD prevalence in Traveller participants in the present study aligns with results from other genetically isolated populations. For example, Pingelap Atoll, a Micronesian island in the South Pacific, is known as 'colourblind island' due to its high prevalence of monochromatism (10 per cent). ${ }^{28}$ Likewise, reported CVD prevalence was higher in Israeli Arabs (12.0 per cent), Ashkenazi Jews (9.1 per cent) ${ }^{29}$ and in the Samaritan community in Israel ( 28 per cent). ${ }^{30}$ 


\begin{tabular}{|c|c|c|c|c|c|c|}
\hline Location & $\begin{array}{l}\text { Number of } \\
\text { participants }\end{array}$ & Test used & Age (years) & $\begin{array}{l}\text { CVD prevalence } \\
\text { in males }\end{array}$ & $\begin{array}{l}\text { CVD prevalence } \\
\text { in females }\end{array}$ & $\begin{array}{l}\text { Breakdown } \\
\text { male }\end{array}$ \\
\hline $\begin{array}{l}\text { Ireland Eye Study } \\
\text { (present study) }\end{array}$ & $\begin{array}{l}1,626 \\
881 \mathrm{M} \\
745 \mathrm{~F}\end{array}$ & $\begin{array}{l}\text { Richmond Hardy- } \\
\text { Rand-Rittler test } \\
\text { (4 } 4^{\text {th }} \text { edition) }\end{array}$ & $6-7$ and $12-13$ & $8.3 \%$ & $1.8 \%$ & $\begin{array}{l}\text { Deutan } 4.8 \% \\
\text { Protan } 1.7 \% \\
\text { Tritan } 0.5 \% \\
\text { Monochromatic } \\
0.1 \%\end{array}$ \\
\hline England $^{25}$ & $\begin{array}{l}513 \\
285 \mathrm{M} \\
255 \mathrm{~F}\end{array}$ & $\begin{array}{l}\text { Ishihara } \\
\text { Verhalgen } \\
\text { Pflugertrident } \\
\text { test }\end{array}$ & $3-11$ & $6.6 \%$ & $0.4 \%$ & NA \\
\hline Nepal ${ }^{26}$ & $\begin{array}{l}2,001 \\
1,050 \mathrm{M} 951 \mathrm{~F}\end{array}$ & Ishihara & 10 & $3.9 \%$ & $0 \%$ & $\begin{array}{l}\text { Deutan } 3.25 \% \\
\text { Protan } 0.09 \%\end{array}$ \\
\hline Singapore $^{4}$ & $\begin{array}{l}1,249 \\
612 \mathrm{M} \\
637 \mathrm{~F}\end{array}$ & Ishihara & $13-15$ & $\begin{array}{l}\text { 5.4\% Chinese } \\
4.9 \% \text { Malay } \\
4.9 \% \text { Indian }\end{array}$ & $0.2 \%$ & NA \\
\hline$U_{S A^{3}}$ & 6,768 & $\begin{array}{l}\text { Ishihara } \\
\text { American-Optical } \\
\text { Hardy-Rand-Rittler } \\
\text { test }\end{array}$ & $12-17$ & $\begin{array}{l}\text { 7.5\% overall } \\
6.4 \% \text { African- } \\
\text { American } \\
7.7 \% \text { White } \\
5.3 \% \text { other races }\end{array}$ & $\begin{array}{l}0.6 \% \text { overall } \\
0.15 \% \text { African- } \\
\text { American } \\
0.7 \% \text { White } \\
0.0 \% \text { other races }\end{array}$ & $\begin{array}{l}\text { Deutan } 4.1 \% \\
\text { Protan } 1.7 \%\end{array}$ \\
\hline Korea ${ }^{33}$ & $\begin{array}{l}4,678 \mathrm{M} \\
4,760 \mathrm{~F}\end{array}$ & $\begin{array}{l}\text { American-Optical } \\
\text { Hardy-Rand-Rittler } \\
\text { test }\end{array}$ & $\begin{array}{l}\text { Third-grade } \\
\text { middle school } \\
\text { ( 15 years } \\
\text { old, age not } \\
\text { specified) }\end{array}$ & $5.9 \%$ & $0.44 \%$ & $\begin{array}{l}\text { Deutan } 3.21 \% \\
\text { Protan } 1.71 \% \\
\text { Unclassified } \\
0.98 \%\end{array}$ \\
\hline$U_{S A}^{5}$ & $\begin{array}{l}\text { 4,177 } \\
1,265 \text { Black } \\
812 \text { Asian } \\
1,280 \text { Hispanic } \\
820 \mathrm{NHW}\end{array}$ & $\begin{array}{l}\text { Colour vision } \\
\text { testing } \\
\text { made easy } \\
\text { American-Optical } \\
\text { Hardy-Rand-Rittler } \\
\text { test }\end{array}$ & 30-72 months & $\begin{array}{l}\text { 1.4\% Black } \\
\text { 3.1\% Asian } \\
\text { 2.6\% Hispanic } \\
5.6 \% \text { NHW }\end{array}$ & $\begin{array}{l}0 \% \\
-0.5 \%\end{array}$ & $\begin{array}{l}\text { Deutan } 51 \% \\
\text { Protan } 34 \%\end{array}$ \\
\hline
\end{tabular}

Table 3. The prevalence of CVD in the Ireland Eye Study and previous studies in other countries involving children

A more recent study, which involved six Muslim populations in Manipur in India, found a prevalence of CVD of 14.9 per cent in the Meiti male participants and 2.9 per cent in the Meiti females. ${ }^{31}$ The authors postulated the higher prevalence was due to the high frequency of consanguineous marriages in this population. ${ }^{31}$ Consanguineous marriages are estimated at 71 per cent in the Traveller community, leading to a higher prevalence of metabolic conditions with autosomal recessive inheritance, ${ }^{21}$ mainly due to homozygous mutations. Social exclusion and isolation reinforce these figures. ${ }^{21}$

The test used to identify CVD may affect the apparent prevalence overall, and of CVD type, hence inter-study comparisons are challenging: for instance, the Ishihara test does not detect tritan defects ${ }^{23}$ and is less successful than the Hardy-Rand-Rittler for differentiation of protan and deutan CVDs. ${ }^{32}$ The present study used the fourth edition of the HardyRand-Rittler pseudoisochromatic plates. This edition is reported to have a sensitivity of 1.00 and specificity of 0.975 when the criterion for failed screening is two or more failed plates. ${ }^{23}$ Cole et al. ${ }^{23}$ found the Hardy-Rand-Rittler test to be as good as the Ishihara for the detection of red-green CVD and preferable for the detection of the tritan defects. However, the authors added the severity of CVD ought to be confirmed with other tests such as the Farnsworth D15 and the anomaloscope, ${ }^{23}$ which was not possible in the present study due to a large number of other ocular measurements in the Ireland Eye Study.

Slaby and Roberts screened 6,768 12-17-year-old American participants in 1974 using the Ishihara test and subsequently tested those who failed Ishihara screening using an earlier (second edition) AmericanOptical Hardy-Rand-Rittler test. ${ }^{3}$ The authors reported several participants who failed the Ishihara screening subsequently passed Hardy-Rand-Rittler rescreening and were then re-categorised as having normal colour vision. ${ }^{3}$ Kim et al. also used the AmericanOptical Hardy-Rand-Rittler test when investigating the prevalence of CVD in a Korean population in 1989 and referred to the issue that mild red-green defects can be missed. ${ }^{33}$ Moreover, Birch found the sensitivity and specificity of the American-Optical Hardy-Rand-Rittler test screening plates were lower than Ishihara screening but noted this test was superior for grading of red-green CVD and ought to be used when Ishihara screening has failed. ${ }^{32}$ However, more recent research has demonstrated the revised Hardy-Rand-Rittler test (Richmond fourth edition) is better at differentiating protans and deutans and should be the test of choice when using only one test for colour vision. ${ }^{23,25}$ While the Nagel anomaloscope is the recommended gold standard when examining CVD, ${ }^{23}$ the cost and non-portability make it an unrealistic screening tool. ${ }^{4}$

The original Hardy-Rand-Rittler test was designed to be used under CIE source $C{ }^{34}$ Natural daylight was used to mimic this with the test presented beside a window, while ensuring direct lighting from tungsten and fluorescent lamps did not reach the plates.

Nonetheless, lighting was impossible to standardise due to different test locations and daylight levels. Although hue discrimination, 
for example, on the FM100 test, by both colour-normal and CVD persons is significantly affected by illuminance quantity and colour temperature, the impact of varying colour temperature on patients' performances on the Hardy-Rand-Rittler test is less significant than might be expected. ${ }^{35}$ However the effect of colour temperature on tritan performance is unreported.

The four participants categorised as tritan were two sets of twin brothers (two of which were Travellers aged seven years and two White 12-year-olds); as tritan CVD is extremely rare (one in 13,000 males and females equally) ${ }^{13}$ ideally these participants should be re-examined in standardised lighting conditions using anomaloscopy to confirm study findings. ${ }^{13}$ Similarly, further investigation of the achromatic participant (White, non-Traveller) would have been desirable. While the prevalence of tritan ( 0.5 per cent) and monochromatic (0.1 per cent) CVDs is higher than expected, stochastic variations are likely to be significant when screening for conditions with such low prevalence, given the sample size, but may have been influenced by lighting factors. Moreover, the development of blue/yellow discrimination lags behind red/green and black/white ${ }^{36}$ which may be a factor affecting the seven-year-old tritan twins. Agreement on re-examination is essential to categorise the depth and severity of CVD in standardised testing conditions. However, it was impractical to investigate further impaired colour vision with a diagnostic test such as anomaloscopy in the present study owing to the time constraints of the broader study of which this was only a part.

The association found between socioeconomic disadvantage and CVD contrasts with findings from the 1958 British birth cohort study where social class and unemployment did not differ with congenital colour vision status. ${ }^{37}$ The associations found in the present study may relate to unawareness or reluctance of some parents to recognise problems at school and home caused by CVD, and perhaps decreased likelihood of seeking advice from healthcare professionals to inform teachers of the difficulties faced by children with CVD. Furthermore, Travellers have lower outcomes in terms of education and employment compared to their settled counterparts; only one per cent of Travellers attend third-level education, eight per cent complete second-level, and for 55 per cent primary-level education was the highest level of education obtained. ${ }^{22}$ What is more, Travellers are six times more likely to be unemployed than their settled counterparts. ${ }^{22}$

Ramachandran et al. argued routine screening for CVD in schoolchildren should not be adopted and discontinued as it does not meet routinely accepted criteria for health screening, ${ }^{38}$ as congenital CVD is non-progressive, untreatable and some evidence points to CVD not substantially impacting on educational attainment or social status. ${ }^{37}$ However, this conclusion ignores the influence of CVD on career advice and choice. Normal colour vision is a statutory requirement for some professions such as the defence and security services, and CVD is a barrier in many occupations requiring colour coding, which is critical for safety in maritime and aviation environments to recognise signal lights and in healthcare for patient safety (for example, colour coding of anaesthetics).

Moreover, many occupations involve aesthetic assessment of colour and colour matching (painter, decorator, interior design, and hairdresser). Also, CVD can have a significant impact on everyday life, ${ }^{14}$ such as for protanopes when driving, as red warning lights appear dimmed and response delayed. Cumberland et al. reported CVD did not confer any functional disadvantages in terms of education or employment; however, as they did not analyse protan and deutan CVDs separately, ${ }^{37}$ it is unsurprising results from the present study do not support their conclusion of lack of association. Similarly, the literature review of occupational significance by Ramachandran et al. ${ }^{38}$ also failed to consider separate possible different effects between protans and deutans. As CVD affects career choice and multiple aspects of daily life, ${ }^{14}$ early identification of CVD is vital to prevent frustration with educational progression in affected children; schoolchildren would benefit from knowing about their CVD before they embark on a career path. ${ }^{17}$

Further research in CVD estimates in Ireland should involve the Traveller population, including representative organisations and provide culturally sensitive counselling and support regarding the educational and occupational consequences of CVD.

The associations found between CVD and low birthweight and multiple births are interesting. Eight participants who reported as twins had CVD (six boys [three sets of twin brothers] and two girls [twin sisters]). In all instances when one twin displayed CVD, their twin also displayed CVD. As twins are born earlier than singleton births they tend to be smaller/lower birthweight. Once twin birth was controlled for, the relationship between birthweight and CVD did not remain significant. Also, previous research reported tritan defects are more prevalent in low birthweight, and preterm babies. ${ }^{39}$ The four tritan participants were two sets of twin brothers; however, as the numbers were small, additional research including confirmation of CVD type and depth with anomaloscopy is merited to critically interrogate the potential relationship between twin birth, low birthweight prematurity and CVD. The link if any between CVD and these factors remains unknown and uncertain.

\section{Conclusions}

CVD prevalence in Ireland was similar to other countries with predominantly White populations. This report should alert clinicians to the association between CVD and Traveller ethnicity, twin birth, and lower birthweight. Early screening is essential to determine educational requirements specific to children with CVD and to counsel schoolchildren with CVD in determining their future career path. As Ireland becomes more ethnically diverse, future studies examining CVD prevalence in different ethnic groups in Ireland are recommended.

\section{ACKNOWLEDGEMENTS}

The authors would like to express their appreciation to Professor Kathryn Saunders (NICER study, School of Biomedical Sciences, University of Ulster, County Londonderry, Northern Ireland), Dr Jim Stack (Waterford Institute of Technology, Ireland) and Professor John Kearney (Epidemiology, School of Biological Sciences, Technological University Dublin, Ireland) for their valuable input in the Ireland Eye Study. In addition, the authors would like to acknowledge the support and participation of the schools, the children and their parents and guardians in the Ireland Eye Study.

This work was supported by the Technological University Dublin Fiosraigh grant, the Opticians Board, and the Association of Optometrists Ireland.

\section{REFERENCES}

1. Birch J. Congenital colour deficiency. In: Diagnosis of Defective Colour Vision, 2nd ed. Oxford: ButterworthHeinemann, 2003.

2. Deeb SS. Molecular genetics of colour vision deficiencies. Clin Exp Optom 2004; 87: 224-229. 
3. Slaby D, Roberts J. Color vision deficiencies in youths 12-17 years of age, United States. Vital Health Stat 11 1974; 134: 1-41.

4. Chia A, Gazzard G, Tong L et al. Red-green colour blindness in Singaporean children. Clin Exp Ophthalmol 2008; 36: 464-467.

5. Xie JZ, Tarczy-Hornoch K, Lin J et al. Color vision deficiency in preschool children: the multi-ethnic pediatric eye disease study. Ophthalmology 2014; 121: 1469-1474.

6. Birch J. Worldwide prevalence of red-green color deficiency. J Opt Soc Am A 2012; 29: 313-320.

7. Grosvenor T. Refractive state, intelligence test scores, and academic ability. Am J Optom Arch Am Acad Optom 1970; 47: 445-450.

8. Elston RC, Forthofer R. Testing for Hardy-Weinberg equilibrium in small samples. Biometrics 1977; 33: 536-542.

9. Merbs SL, Nathans J. Absorption spectra of the hybrid pigments responsible for anomalous color vision. Science 1992; 258: 464-466.

10. Simunovic MP. Colour vision deficiency. Eye 2010; 24 747-755.

11. Taylor WO. Effects on employment of defects in colour vision. Br J Ophthalmol 1971; 55: 753-760.

12. Siegel RB. Discrimination in the eyes of the law: how color blindness discourse disrupts and rationalizes social stratification. Calif Law Rev 2000; 88: 77-118.

13. Cole BL. Assessment of inherited colour vision defects in clinical practice. Clin Exp Optom 2007; 90: 157-175.

14. Steward JM, Cole BL. What do color vision defectives say about everyday tasks? Optom Vis Sci 1989; 66: 288-295.

15. Tagarelli A, Piro A, Tagarelli G. Genetic, epidemiologic and social features of colour blindness. Public Health Genomics 1999; 2: 30-35.

16. Gallo PG, Panza M, Lantieri PB et al. Some psychological aspects of colour blindness at school: a field study in Calabria and Basilicata (southern Italy). Color Res App/ 2003; 28: 216-220.

17. Long JA, Honson V, Katalinic $P$ et al. Re: is screening for congenital colour vision deficiency in school students worthwhile? A review. Clin Exp Optom. 2015; 98: 192.

18. Johnston W, Cheeseman EA, Merrett JD. Observations on routine medical Examinations of University Entrants in Northern Ireland. BrJ Prev Soc Med 1957; 11:152-161.

19. Harrington SC, Stack J, Saunders K et al. Refractive error and visual impairment in Ireland schoolchildren. Br J Ophthalmol 2019; 103: 1112-1118.

20. Gilbert E, Carmi S, Ennis S et al. Genomic insights into the population structure and history of the Irish Travellers. Sci Rep 2017; 7: 42187.

21. Lynch SA, Crushell E, Lambert DM et al. Catalogue of inherited disorders found among the Irish Traveller population. J Med Genet 2018; 55: 233-239.

22. Watson D, Kenny O, Mcginnity F. A Social Portrait of Travellers in Ireland. Dublin; 2017. Available from: www.esri.ie. Accessed January 8, 2020.

23. Cole BL, Lian K-Y, Lakkis C. The new Richmond HRR pseudoisochromatic test for colour vision is better than the Ishihara test. Clin Exp Optom 2006; 89: 73-80.

24. Bailey J, Neitz M, Tait D et al. Evaluation of an updated HRR color vision test. Vis Neurosci 2004; 21: 431-436.

25. Birch J, Platts CE. Colour vision screening in children: an evaluation of three pseudoisochromatic tests. Ophthalmic Physiol Opt 1993; 13: 344-349.

26. Shrestha RK, Joshi MR, Shakya S et al. Color vision defects in school going children. I Nepal Med Assoc 2010; 50: 264-266.

27. Gilmartin M. The changing landscape of Irish migration, 2000-2012. Irish Geogr 2013; 46: 91-111.

28. Hussels IE, Morton NE. Pingelap and Mokil atolls: achromatopsia. Am J Hum Genet 1972; 24: 304-309.
29. Adam A, Doron D, Modan R. Frequencies of protan and deutan alleles in some Israeli communities and a note on the selection-relaxation hypothesis. Am J Phys Anthropol 1967; 26: 297-305.

30. Bonné B. Genes and phenotypes in the Samaritan isolate. Am J Phys Anthropol 1966; 24: 1-19.

31. Shah A, Hussain R, Fareed M et al. Prevalence of redGreen color vision defects among Muslim males and females of Manipur. India Iran J Public Health 2013; 42: 16-24.

32. Birch J. Efficiency of the Ishihara test for identifying red-green colour deficiency. Ophthalmic Physiol Opt 1997; 17: 403-408.

33. Kim H, Lee $\mathrm{S}$, Choe J. The incidence of congenital color deficiency among Koreans. J Korean Med Sci 1989; 4: 117-120.

34. Hardy LH, Rand G, Rittler MC. H-R-R polychromatic plates*. J Opt Soc Am 1954; 44: 509.

35. Dain SJ. Illuminant and observer metamerism and the Hardy-Rand-Rittler color vision test editions. Vis Neurosci 2006; 23: 685-694

36. Ling BY, Dain SJ. Development of color vision discrimination during childhood: differences between blueyellow, red-green, and achromatic thresholds. J Opt Soc Am A 2018; 35: B35-B42.

37. Cumberland P, Rahi JS, Peckham CS. Impact of congenital colour vision deficiency on education and unintentional injuries: findings from the 1958 British birth cohort. BMJ 2004; 329: 1074-1075.

38. Ramachandran N, Wilson G, Wilson N. Is screening for congenital colour vision deficiency in school students worthwhile? A review. Clin Exp Optom 2014; 97: 499-506.

39. Dobson V, Quinn GE, Abramov I et al. Color vision measured with pseudoisochromatic plates at fiveand-a-half years in eyes of children from the CRYOROP study. Investig Ophthalmol Vis Sci 1996; 37: 2467-2474. 